DOI: 10.17805/trudy.2017.2.2

\title{
ТЕЛЕСНО-ЭНЕРГИЙНЫЙ ПОДХОД К ПОНИМАНИЮ ПСИХОЛОГИЧЕСКОЙ ГРАНИЦЫ ЧЕЛОВЕКА
}

\author{
Т. С. Леви \\ Московский гуманитарный университет
}

\begin{abstract}
Аннотация: Встатье анализируется понятие телесность и излагается суть телесно-энергийного подхода к пониманию психологической границы человека; феномен психологической границы рассматривается с позиции концепции А. А. Ухтомского о функциональном органе; представлена структурно-функциональная модель психологической границы, в которой единицей анализа выступает действие, направленное на решение задач взаимодействия человека с миром.
\end{abstract}

Ключевые слова: телесность; энергия; психологическая граница; функциональный орган; функции психологической границы; телесно-энергийный подход

\section{CORPORAL AND ENERGY APPROACH TO THE UNDERSTANDING OF A HUMAN'S PSYCHOLOGICAL BOUNDARY}

\author{
T. S. Levi \\ Moscow University for the Humanities
}

\begin{abstract}
The paper analyses the concept of corporality and outlines the essence of the corporal and energy approach to the understanding of a human's psychological boundary. The phenomenon of a human's psychological boundary is looked upon from the perspective of A. A. Ukhtomsky's conception of the functional organ. The paper also presents the structural and functional model of psychological boundary, in which the unit of analysis is the action solving the problem of a human's interaction with the world.
\end{abstract}

Keywords: corporality; energy, psychological boundary; functional organ; functions of a psychological boundary; corporal and energy approach

Душа и тело в современной европейской культуре существуют как полюса оппозиции и соответствующий дуализм присущ изучающим их наукам. Введение понятия «телесность», как отмечалось нами в предисловии к сборнику «Психология телесности между душой и телом», имеет методологическое значение, так как телесность, находясь между душой и телом, и тем самым формируя единое пространство, позволяет изучать психологические феномены в их естественной целостности (Леви, 2005). Если «тело» означает, прежде всего, физический объект, не несу- 
щий субъектности, духовности, то «телесность» - есть одухотворенное тело, имеющее энергетическую сущность, проявляющуюся в живом движении. Человеческая телесность является результатом процесса онтогенетического, личностного развития - в широком смысле исторического развития и выражает культурную, индивидуально-психологическую и смысловую составляющие уникального человеческого существа (там же). Таким образом, прилагательные «телесная», «телесный» и т. п. могут использоваться как в узком, так и в широком смысле слова. В узком смысле, как производные от существительного «тело», когда речь идет о физической составляющей человека. В широком смысле, как производные от существительного «телесность», когда говорится о динамической живой форме, неотделимой от эмоциональной и ментальной жизни человека.

Тело и телесность отличает мера жизненности. Представьте себе фактор, на одном конце которого тело, лишенное энергии жизни - мертвое тело (телесность 0\%), а на другом максимально одухотворенное тело (телесность 100\%). Движение по фактору в сторону увеличения телесности означает все большую интеграцию физического и духовного начал, и соответственно тело будет аккомулировать в себе и пропускать через себя все больше энергии. Движение в обратном направлении означает отчуждение человека от своего тела, а, следовательно, телесная энергетика будет постепенно ослабевать. По мнению В. Подороги, состояние тела можно определить по способности пропускать через себя различные виды внешних и внутренних энергий (Подорога, 1995).

Существует закономерность: чем более человек отчужден от своего тела, тем более выражена психологическая проблематика. Крайняя степень разотождествления с собственным телом наблюдается у больных шизофренией: физическое тело не признается как часть Я. Я, для больного шизофренией - это внутренний мир, эмоции, мысли, а тело - как физический субстрат - часть внешнего материального мира. Как пишет В. Подорога: «Связка Я-тело - Другой-Мир замещается иной: Я - ТелоДругой-Мир» (там же: 28).

Отсутствие контакта с собственным телом, отчуждение от него характерно для людей, страдающих наркоманией. Сенсорная бедность и негативный локус телесных ощущений тесно связаны с нежеланием быть «здесь и теперь», стремлением уйти в другую реальность (Леви, 2011). Тоже самое можно сказать и о других видах зависимостей: алкогольной, игровой, компьютерной и др. - человеку невыносимо в пространстве своего тела, т. к. он не может справиться с внутренним напряжением или чувством пустоты и безжизненности, и тогда создаются замещающие пространства.

Потеря остроты чувств, восприятие своего жизненного пространства как сузившегося характерно для состояния депрессии. Д. Хелл пи- 
шет, что в состоянии депрессии «собственное тело воспринимается менее одушевленным, чем прежде, а в экстремальных случаях - как пустая оболочка» (Хелл, 1999: 43). Для рисунков людей с депрессивными состояниями характерно изображение кукольного, не человеческого тела, часто полностью скрытого под одеждой и маской. Идентификация с подобной телесностью дает переживание серости, безрадостности, зажатости миром, невозможности осуществления самоидентичных движений в мире и поэтому отсутствие себя. Ибо мы обнаруживаем свое присутствие в этом мире через собственные движения, действия.

Отчужденность от своего тела проявляется в многообразной психологической проблематике: психосоматической, сексуальной, пищевой и эмоциональной зависимостях, чувстве одиночества и экзистенциальном вакууме. При выраженной психологической проблематике тело переживается как корка, препятствующая взаимодействию внутреннего и внешнего миров. Тело - корка блокирует движение энергии. Состояния психологического благополучия, напротив, сопровождаются переживанием своего тела в единстве со своей душевной сущностью. Тело превращается в телесность. Телесность обретает целостность, силу и наполненность энергией жизни, благодаря единению с энергией окружающего мира.

Таким образом, существование человеческого тела, отграничивающего «каплю энергии» отдельного человека от энергии окружающего пространства является необходимым условием человеческой жизни, но, вместе с тем, важно, чтобы живое тело не было телом-коркой и не становилось преградой на пути развития телесности человека.

Телесность предполагает наличие особой границы, которая с одной стороны, защищает нашу психику от разрушающих внешних воздействий, а с другой пропускает необходимые для нас энергии. Она обеспечивает нам возможность выражать себя в мире и, вместе с тем, сдерживать, «контейнировать» определенную внутреннюю энергию. Речь идет о психологической границе, которая не совпадает с границей физического тела, очерченной кожей (Леви, 2008: 23). В. А. Подорога подчеркивает, что следует различать границу организма и границу жизни. По его мнению, граница жизни (в нашей терминологии «психологическая граница») «является виртуальной ... границей, изменяющей в каждое последующее мгновение предыдущий образ нашего тела, и мы даже не всегда «схватываем» эти мгновенные изменения; порой эта граница смещается столь далеко за предписанные организмом пределы, что не в силах вернуться к исходной физиологической границе, - то, напротив, сжимается, наподобие шагреневой кожи, ускользает от себя в глубины Внутреннего» (Подорога, 1995: 51).

Феномен границы имеет фундаментальное значение: возникновение любой субстанции связано с выделением ее из окружающего пространства. Взаимодействие с окружающим пространством является не- 
обходимым условием жизни и осуществляется на границе жизненного образования. К. Ясперс пишет: «Любая жизнь проявляет себя как постоянный обмен между внутренним миром и окружающим миром» (Ясперс, 1999: 37). На внутриутробной стадии развития ребенка, его взаимодействие с окружающим миром опосредуется матерью. Пространство матери выступает в качестве буфера, люфта, пропускающего одни энергии и задерживающего другие. После рождения ребенка мать и близкие взрослые продолжают выступать в качестве буфера, организующего и осуществляющего его взаимодействие с миром. Вся ответственность за то, что происходит с ребенком лежит на взрослых, которые реализуют функции еще не сложившейся психологической границы ребенка в соответствии со своими представлениями о его благе. Рассматривая историю возникновения психологической границы в онтогенезе, В. А. Подорога пишет: «Ребенок и мать - находятся под одним (материнским) покровом... Все ощущения, связанные с формированием психического Эго ребенка определяются самым ближайшим к нему Другим. Этот Другой всегда будет его второй кожей, которой ему всегда будет недоставать. И эта вторая кожа не только являет собой нечто вроде панцирной защиты, но и может оказаться самым опасным врагом первой» (Подорога, 1995: 47). И далее «... всякая попытка реконструкции психического Эго определяется учетом взаимодействия первой и второй кожи и без последней, собственно, никакое психическое Эго не в силах ни сформироваться, ни проявить себя. Именно вторая кожа открывает этот, не всегда безопасный путь в мир других тел, к телу Другого, но вторичным ходом - путь к своему телу» (там же: 48). В процессе развития ребенок постепенно учится сам взаимодействовать с окружающим миром, принимая ответственность за свои действия на себя. Ему предстоит освободиться от «второй родительской кожи», взяв на себя все функции, которые она выполняла. Развитие личности в онтогенезе неразрывно связано с выстраиванием собственной психологической границы, т. е. системы действий по решению конкретных задач взаимодействия с миром. Психологическая граница формируется в процессе осознания человеком своего собственного внутреннего пространства и его отстаивания, преодоления симбиотических отношений. Такое преодоление означает обретение права на самоопределение, свободу, но, вместе с тем, и ответственность за себя. Сформированная психологическая граница взрослого человека позволяет ему осуществлять взаимодействие с миром, соответствующее его возможностям, мотивам и ценностям. Адекватное и дифференцированное восприятие человеком границы физического тела, способствует переживанию «Я есть» и является фундаментом самоидентичности. Осознание и оптимизация психологической границы обеспечивают переживание «Я могу» и являет- 
ся основой активности человека. Если граница физического тела остается после смерти человека, то психологическая граница - «граница жизни» исчезает вместе с самой жизнью, так как она есть функция жизни. Граница физического тела существует субстанционально. Психологическая граница имеет не субстанциональную, а энергийную природу: те или иные ее характеристики возникают как временное сочетание сил для решения задачи осуществления конкретного взаимодействия человека с миром. Психологическая граница проявляется в активности человека, в его действиях. Она существует не субстанционально, но вместе с тем актуально, и, следовательно, является виртуальным образованием. Вышесказанное свидетельствует, что психологическая граница является не морфологическим, а функциональным органом.

Как мы уже писали, идея функциональных органов разрабатывалась А. А. Ухтомским (Леви, 2008). Многие знают А. А. Ухтомского, прежде всего, как физиолога. Однако, как подчеркивает В. П. Зинченко, целью его исследований стало «познание анатомии и физиологии человеческого духа, духовного организма - не тела, не мозга, а души и духа; может быть, точнее, не только тела, не только мозга, а их вместе с духовным организмом» (Зинченко, 2000: 82). По мнению А. А. Ухтомского, именно функциональные органы, в своей совокупности, образуют духовный организм человека. Согласно А. А. Ухтомскому, функциональный орган это не морфологическое, а энергийное образование - сочетание сил, способное осуществить определённое достижение. В. П. Зинченко подчеркивает, что «важнейшая черта функциональных органов состоит в том, что они существуют виртуально и наблюдаемы, да и то лишь частично, в исполнении, т. е. в активности, в том числе и в активном покое, в действии, в поступке» (Зинченко, 2003: 658).

Таким образом, психологическую границу можно рассматривать как виртуально-энергийное образование, функциональный орган, в понимании А. А. Ухтомского. Если граница тела обозначена кожей - анатомическим органом, то граница телесности обозначена движениями и действиями человека - функциональным органом.

Что собой представляет структура уже сложившейся психологической границы и каково ее функционирование? Ткань психологической границы составляют действия, совершаемые человеком в целях решения задач взаимодействия с миром. Действия, оказываясь на границе между внутренним и внешним, с одной стороны, репрезентируют внутреннее, а с другой, как бы упираются во внешнее. Факт совершения действия объективирует внутренний мир человека. Как пишет В. Ф. Гегель: «Только в действии индивидуальность действительна». По мнению С. Л. Рубинштейна, действие является основной «клеточкой» психологии, так как в 
действии психологический анализ может вскрыть зачатки всех элементов психологии и всякое действие исходит из тех или иных побуждений (Рубинштейн, 1989). Действие, в данном подходе, рассматривается как единица анализа психологической границы.

В чем состоят функции психологической границы? Для решения каких задач выполняются действия?

Для того, чтобы:

1. Защитить себя, противодействовать внешним воздействиям, если эти воздействия оцениваются как вредные - невпускающая функция;

2. Пропустить внешние воздействия, если они оцениваются как полезные - проницаемая функция;

3. Вобрать желаемое из внешнего пространства - вбирающая функция;

4. Выразить себя, пропустить из внутреннего во внешнее - отдающая функция;

5. Сдержать себя, не пропустить внутреннее во внешнее - сдерживающая функция;

6. Удерживать спокойное равновесие на границе - спокойнонейтральная функция.

Таким образом, психологическую границу можно рассматривать как структуру, состоящую из 6 функциональных образований. Функции соответствуют задачам, которые стоят перед личностью. В зависимости от задачи, которую человек решает в данный момент, активизируется и проявляется в действиях та или иная функция. Функции психологической границы выступают как сопряженные доминанты (используя терминологию А. А. Ухтомского). Функциональный орган - психологическая граница, являясь ведущей доминантой, реализуется как система из шести сопряженных (рядоположенных) субдоминант - функций. Функциональный орган задействует различные личностные структуры для решения задачи. Действия, проявляющиеся на границе, результируют в себе различные уровни личностной организации: потребности, установки, эмоциональные состояния и др., которые выступают в качестве уровней или этажей функционального органа. Функционально-структурная модель психологической границы более подробно представлена нами в одноименной статье (Леви, 2015). Данная модель рассматривает психологическую границу как уже сложившееся образование.

Важнейшими интегративными характеристиками психологической границы являются ее сила и сбалансированность. Сила психологической границы складывается из сил ее 6-ти функций. Сила функции - есть выражение усилия, энергии, направленной на решение задачи. Возможность осуществления действия на основе принятого личностью решения 
является показателем сформированности функции, ее силы. Например, если человек считает нужным заявить о своей потребности, так чтобы она была услышана и чтобы ее учли, он может вложить в выражение своей потребности и достижение результата столько энергии, сколько адекватно в данной ситуации (вбирающая функция). Можно сказать, что вбирающая функция слабо сформирована, если человек считает нужным заявить о своей потребности, но стесняется это сделать, надеется, что все как-то решиться само собой, т.е. не вкладывает энергию в действия на границе. Если все 6 функций хорошо сформированы, то психологическая граница является сильной (суммарный показатель). Вместе с тем, такая граница является сбалансированной. Сбалансированность проявляется в приблизительно одинаковой выраженности силы функций. Однако функции могут быть не сбалансированы между собой. Например, человек может активно выражать свое состояние, если это нужно (отдающая функция), но сдерживать себя ему сложно (сдерживающая функция). В этом случае отдающая функция сильная, а сдерживающая - слабая. Такой дисбаланс функций ослабляет психологическую границу в целом и выражается в определенной картине поведения. Варианты дисбаланса 6 функций создают типы психологической границы, которые выражаются в поведенческих симптомокопмлексах. Варианты дисбаланса и некоторые типы психологической границы исследованы и описаны нами в ряде работ (Леви, 2013; Леви, Дрозд, 2014).

Представьте себе клавиши рояля. Под воздействием пальцев музыканта то или иное сочетание клавиш будет создавать определенную музыку. Если все клавиши исправны - любые варианты звучания возможны (мелодии, аккорды и т. п.). Музыка существует виртуально в сознании музыканта, но материализуется она в звуке через нажатие клавиш. Если какие-то клавиши западают - как бы музыкант не стремился выразить себя - звучание определенных мелодий и аккордов становится невозможным: одни звуки хорошо слышны, других - не слышно. 6 функций психологической границы - как клавиши рояля: если какие-то функции «западают» - поведение приобретает определенное звучание.

Показателями сформированной (оптимальной) психологической границы будут являться относительно высокие и относительно сбалансированные показатели по всем функциям. Высокие показатели по функциям границы говорят о высокой энергетичности границы, низкие - об астенизации границы.

Психологическая граница развивается и изменяется на протяжении всей нашей жизни. По сути дела, качество границы есть выражение внутреннего, энергетического и соответственно психологического состояния человека. Процесс формирования оптимальной границы означает ско- 
рее вектор движения к возможному, более совершенному Я. Оптимальная психологическая граница, представляет собой выстроенный в процессе жизненного пути усилиями самого человека функциональный орган. Оптимально функционирующая, т. е. сильная и сбалансированная психологическая граница, является необходимым условием аутентичного взаимодействия человека с окружающим миром. Она позволяет осуществлять избирательную интериоризацию и аутентичное самовыражение (экстериоризацию). Избирательная интериоризация обеспечивается функциями: невпускающей, проницаемой и вбирающей. Избирательная экстериоризация обеспечивается функциями: отдающей и сдерживающей. Оптимальная граница позволяет осуществлять такой обмен энергиями между внутренним и внешним пространствами, при котором сохраняется динамическая целостность человека в единстве с окружающим миром.

\section{СПИСОК ЛИТЕРАТУРЫ}

Зинченко, В. П. (2000) Алексей Алексеевич Ухтомский и психология (К 125-летию со дня рождения) // Вопросы психологии. № 4. С. 79-97.

Зинченко, В. П. (2003) Преходящие и вечные проблемы психологии // Аткинсон Л. Р., Аткинсон Р. С. и др. Введение в психологию. М. : Прайм Еврознак. 672 с. С. 649-662.

Леви, Т. С. (2005) От составителя // Психология телесности между душой и телом / ред.-сост. В. П. Зинченко, Т. С.Леви. М. : Изд-во АСТ. 732 с.

Леви, Т.С. (2008) Пространственно-телесная модель развития личности // Психологический журнал. Т. 29. № 1. С. 23-33.

Леви, Т.С. (2011) Телесная парадигма развития личностной аутентичности. М.: Изд-во МосГУ.190 с.

Леви, Т. С. (2013) Диагностика психологической границы личности: качественный анализ // Вопросы психологии. № 5. С. 93a-101.

Леви, Т. С., Дрозд, И. А. (2014) Особенности эмоциональных состояний людей с разными типами психологической границы личности // Научное обозрение. Серия 2. Гуманитарные науки, вып. № 2. С. 68-72.

Леви, Т. С. (2015) Структурно-функциональный подход к диагностике и коррекции психологической границы личности // Журнал практического психолога. № 4. С. 14-25.

Рубинштейн, С. Л. (1989) Основы общей психологии : в 2 т. М. : Педагогика.

Подорога, В. (1995) Феноменология тела. M. : Ad Marginem. 339 с. Хелл, Д. (1999) Ландшафт депрессии / пер. с нем. М. : Алетейя. 277 с. Ясперс, К. (1997) Общая психопатология. М. : Практика. 1053 с.

Дата поступления: 15.04.2017 2. 
Леви Татьяна Самуиловна - кандидат психологических наук, доцент, профессор кафедры общей психологии и истории психологии Московского гуманитарного университета. Адрес: 111395, Россия, г. Москва, ул. Юности, д. 5. Тел.: +7 (499) 374-67-20. Эл. адрес: levitasa36@yandex.ru

Levi Tatiana Samuilovna, Candidate of Psychology, Associate Professor, Professor, Department of General Psychology and History of Psychology, Moscow University for the Humanities. Postal address: 5, Yunosti St., Moscow, Russian Federation 111395. Tel.: +7 (499) 374-67-20. E-mail: levitasa36@ yandex.ru

\section{Для цитирования:}

Леви Т. С. Телесно-энергийный подход к пониманию психологической границы человека [Электронный ресурс] // Научные труды Московского гуманитарного университета. 2017, № 2. URL: http://journals.mosgu.ru/trudy/article/view/448 (дата обращения: дд.мм.гг.). DOI: 10.17805/trudy.2017.2.2 